\title{
ALTERAÇÃO DE PLAGIOCLÁSIOS DOS RIODACITOS DA FORMAÇÃO SERRA GERAL (JKsg) DA REGIÃO DE PIRAJU - SP ${ }^{1}$
}

\author{
Silvia Alessandra Truffi ${ }^{2,4}$; Celso Augusto Clemente $^{3 *}$ \\ ${ }^{2}$ Pós-Graduanda em Solos e Nutrição de Plantas - USP/ESALQ. \\ ${ }^{3}$ Depto. de Solos e Nutrição de Plantas - USP/ESALQ, C.P. 9 - CEP: 13418-900 - Piracicaba, SP. \\ ${ }^{4}$ Bolsista CAPES. \\ *Autor correspondente<clemente@esalq.usp.br>
}

\begin{abstract}
RESUMO: A região de Piraju - SP é caracterizada geologicamente por apresentar uma grande distribuição de rochas básicas e ácidas da Formação Serra Geral. Os processos e produtos de alteração das rochas básicas são apresentados em muitos trabalhos, mas estudos envolvendo alteração de rochas vulcânicas ácidas são raros. Apresentam-se os resultados de estudos petrológicos, químicos e mineralógicos nas rochas vulcânicas ácidas (riodacitos da Formação Serra Geral), nos produtos de alteração dessas rochas, dando ênfase para a evolução mineralógica dos plagioclásios. Os riodacitos da Fm. Serra Geral (JKsg) possuem em sua composição mineralógica cerca de $60-65 \%$ de plagioclásios configurando assim a parte mais importante de sua constituição. O estudo da alteração desses plagioclásios oferece informações importantes em relação a própria alteração da rocha e dos solos relacionados. Resultados obtidos a partir de análises de microscopia óptica, difratometria de raios- $X$ aliados a determinações químicas qualitativas e semi-quantitativas obtidas por microscopia eletrônica de varredura (MEV) permitiram importantes interpretações e conclusões sobre a evolução da alteração nos plagioclásios, a saber: a) por meio de intemperismo não muito intenso, isto é, processo de hidrólise parcial (monossialitização) os cristais de plagioclásio evoluem principalmente para caulinita e secundariamente para mica e haloisita; b) por meio de intemperismo intenso, isto é, processo de hidrólise total (alitização) os cristais de plagioclásio evoluem para gibbsita.
\end{abstract}

Palavras-chave: riodacito, plagioclásio, hidrólise, caulinita, gibbsita

\section{ALTERATIONS OF PLAGIOCLASES OF THE RHYODACITES FROM THE SERRA GERAL FORMATION (JKsg) OF PIRAJU (SP) BRAZIL}

\begin{abstract}
The Piraju (SP) Brazil area is geologicaly characterized by a great distribution of basic and acid rocks from the "Serra Geral" Formation. Basic rocks have been extensively studied as to their processes and products of alteration. However, published material on the same subject related to volcanic acid rocks is scarce. This research exposes results of studies made in petrologic, mineralogical and micromorphological volcanic acid rocks (rhyodacites of the Serra Geral Formation), in the alterations developed above these rocks, making the mineralogical evolution of plagioclases clear. The rhyodacites of the Serra Geral Formation (JKsg) possess in their mineralogical composition about $60-65 \%$ of plagioclases, (macro and fenocrystals) configuring the most important part of their constitution. The study of the alteration of these plagioclases offers important information in relation to the alteration of the rock and related soils. Results obtained by optic microscopy, X-ray diffraction allied to chemical qualitative and semi-quantitative determinations by scanning eletronic microscopy (SEM) analyses allowed important interpretations and conclusions on the evolution of the alteration of the plagioclases: a) through not very intense weathering processes, that is, through a partial hydrolysis process (monossialitization) the plagioclase crystals developed mostly to kaolinite and secondarily to mica and haloysite; $b$ ) through, intense weathering processes, that is, through a total hydrolysis process (alitization) the plagioclase crystals developed to gibbsite.

Key words: rhyodacites, plagioclases, hydrolysis, kaolinite, gibbsite
\end{abstract}

\section{INTRODUÇÃO}

Os derrames vulcânicos, na sua maior parte, são constituídos por rochas basálticas (ocupando mais de $60 \%$ da superfície terrestre), podendo ocorrer tanto nos oceanos, principalmente ao longo de cadeias mesooceânicas, como sobre os continentes, na forma de derrames de platô, como os platô do Deccan (Índia), Karroo (África) e o da Bacia do Paraná (Brasil).

Do ponto de vista petrográfico, os derrames de lavas distribuídos em toda extensão da Bacia do Paraná, foram descritos como sendo basaltos de composição homogênea (Leinz, 1949; Almeida, 1981; Ruegg \& Amaral, 1976).

Bellieni et al. (1986a); Nardy, et al. (1987); Comin-Chiaramont et al. (1988); Piccirillo et al. (1987) mostraram que são dois os principais tipos de rochas: o primeiro expresso pelas rochas básicas (basaltos e andesi-basaltos) e o segundo expresso pelas rochas ácidas (riólitos e riodacitos).

As rochas vulcânicas ácidas constituem estratos (derrames) separados por contatos difusos, diferentemente

${ }^{1}$ Parte da Dissertação de Mestrado da primeira autora, apresentada à USP/ESALQ, Piracicaba, SP. 
dos que ocorrem nos basaltos, onde via de regra verificam-se brechas e juntas discordantes (lyomasa, 1994). Possuem matriz vítrea, parcial ou totalmente devitrificada (em quartzo e feldspato alcalino, com abundância de microcristais de minerais opacos e filossilicatos associados em quantidades menores). Nesta matriz dispõem-se microfenocristais e fenocristais de plagioclásio e piroxênio, por vezes isorientados. A composição mineralógica dos riodacitos da Formação Serra Geral na Bacia do Paraná é simplesmente formada na sua maior parte por plagioclásio $(1 \%$ de macrocristais e $3 \%$ de fenocristais); clinopiroxênio (augita, 0,7\%); pigeonita (aproximadamente 0,1\%); opacos (magnetita-ilmenita, $1 \%$ ) e apatita $(0,2 \%)$. A matriz dessas rochas é composta essencialmente pelos mesmos minerais citados, além de, feldspato alcalino (ortoclásio), quartzo e material vítreo, sendo muito comum a ocorrência de intercrescimento gráfico de quartzo e feldspato alcalino. Em algumas amostras ocorrem vesículas preenchidas por quartzo, sendo a calcita o mineral secundário mais importante (Raposo, 1987).

O estudo isolado de alteração dos minerais dessas rochas podem contribuir na determinação dos processos que levam a transformação de uma rocha em manto de intemperismo e material originário ou parental em solo, tornando-se importante, tanto cientificamente quanto a sua aplicação na pesquisa de melhor uso do solo. Sobre essas rochas as ações intempéricas que ocorrem na natureza e que são extremamente lentas conjugadas levam a transformação do material originário que sob a ação dos processos pedológicos fizeram por desenvolver os solos mais bem aproveitados do Brasil, cujos materiais mereceram e merecem estudos por parte de vários pesquisadores.

Trabalhos referindo-se à alteração superficial da Fm. Serra Geral (JKsg) da Bacia do Paraná não são muitos, destacando-se: Delvigne (1965); Melfi \& Levi (1971); Levi \& Melfi (1972); Menegotto \& Gasparetto (1987); Gonçalves (1987); Clemente (1988) e Gasparetto (1990).

Com a intenção de contribuir com o exposto, foi traçado o objetivo desse trabalho, ou seja, estudar a evolução dos plagioclásios dos riodacitos da Fm. Serra Geral (JKsg).

\section{MATERIAL E MÉTODOS}

\section{Localização}

A área em estudo situa-se na região de Piraju (SP) e apresenta como latitudes as coordenadas $23^{\circ} 00^{\prime}$ a $23^{\circ} 15^{\prime}$ a sul e como longitude as coordenadas $49^{\circ} 15^{\prime}$ a $49^{\circ} 30^{\prime}$ a oeste. A região localiza-se a sudoeste do Estado de São Paulo, às margens do rio Paranapanema, a $331 \mathrm{Km}$ da Capital. O acesso é facilitado pelas Rodovias SP270 (Raposo Tavares) e pela SP280 (Castelo Branco).

\section{Clima}

Os dados referentes aos elementos climáticos térmicos (temperatura) e hídrico (precipitação, umidade, evaporação), permitem identificar, segundo o sistema internacional de Köppen, o clima da região de Piraju como CWA, definido como clima quente, bem demarcado sazonalmente por uma estação de verão quente e chuvosa (temperatura maior que $22^{\circ} \mathrm{C}$ e precipitação no mínimo dez vezes maior que a do mês mais seco) e uma estação de inverno seca e amena (temperaturas mínimas ao redor de $18^{\circ} \mathrm{C}$ e precipitação menor que $30 \mathrm{~mm}$ no mês mais seco).

O índice pluvial da maior parte da região mostra uma precipitação de 1100 a $1300 \mathrm{~mm}$ anuais. Este tipo de clima, leva a transformação da matéria orgânica e a alteração dos constituintes primários das rochas, que condicionam o desenvolvimento de solos formados tipicamente por minerais secundários.

\section{Geologia}

$\mathrm{Na}$ área estudada, ocorrem derrames de lavas básicas, ácidas pertencentes a Formação Serra Geral (Juro-Cretáceo) e intrusivas associadas, além de sedimentos pré e pós vulcânicos, representados principalmente, pelas Formações Botucatu (Juro-Cretáceo) e Bauru (Cretáceo Superior). No topo do planalto basáltico, entre Sarutaiá e Fartura e ao longo do rio Paranapanema, afloram os arenitos da Formação Botucatu, que constituem os principais sedimentos pré-vulcânicos da área estudada.

Sartori \& Maciel Filho (1983) encontram-se entre os primeiros que separaram os derrames ácidos dos básicos da Fm. Serra Geral. Observaram que os derrames ácidos nesta região, ocorrem principalmente ao longo do rio Paranapanema, podendo apresentar estruturas vesiculares e / ou amigdaloidais. Tais derrames foram afetados por um sistema de falhas e fraturas de direção NW-SE, muitas das quais responsáveis pelos contatos com os derrames básicos e os sedimentos de outras formações, aparecendo pequenas lentes de arenitos entre um derrame e outro.

Essas rochas vulcânicas ácidas apresentam uma estrutura tabular bem definida devido a presença de um sistema de juntas horizontais bem desenvolvidas (Nardy et al., 1986). Normalmente são de texturas que variam de fraca a fortemente porfirítica, sendo classificadas principalmente, como riólitos e riodacitos pertencentes ao tipo Chapecó (Bellieni et al., 1986a). Os riodacitos apresentam-se freqüentemente alterados tendo cores que variam de cinza-esbranquiçado a vermelhoamarronzado.

\section{Trabalho de Campo}

A metodologia empregada neste trabalho desenvolveu-se em duas etapas, sendo uma de campo e outra de laboratório. 
$\mathrm{Na}$ viagem ao campo foi realizado 0 reconhecimento geral da área, quanto aos aspectos geológicos, geomorfológicos e pedológicos. Com base nestas observações, selecionou-se uma topossequência que recebeu a denominação de Topossequência Timburi, que se refere a um nome regional dada pela cidade mais próxima. Assim sendo nesta topossequência foram amostrados cinco perfis, P1, P2, P3, P4 e P5 sendo P1 e P5 perfis completos desde a rocha até o horizonte superior do solo e os demais contemplam apenas as camadas de rocha alterada juntamente com os perfis do solo.

\section{Trabalho de Laboratório \\ Microscopia óptica}

O estudo petrográfico sobre lâminas delgadas permite uma caracterização dos constituintes mineralógicos, locais específicos de alteração e suas relações, a partir de amostras não perturbadas.

Os minerais possuem características ópticas específicas (birrefringência, pleocroísmo, clivagens, relevo, ângulo de extinção etc) o que permite a determinação segura dos minerais inalterados, o mesmo não ocorre quando são produtos de alteração, minerais neo-formados ou minerais de transformação, em especial os argilominerais, isto porque, apresentam-se muitas vezes associados a oxi-hidróxidos de Fe que mascaram seus caracteres ópticos próprios.

\section{Análise por Difração de raios-X}

As amostras dos solos e das alterações sofreram um tratamento prévio para eliminação do Fe e da matéria orgânica. Inicialmente foi feita a oxidação da matéria orgânica com peróxido de hidrogênio a $300 \mathrm{~g} \mathrm{~L}^{-1} \mathrm{e}$ a remoção do ferro com citrato de sódio $3 \mathrm{Mol} \mathrm{L}^{-1}$, bicarbonato de sódio $1 \mathrm{Mol} \mathrm{L}^{-1}$ e ditionito de sódio.

\section{Microscopia eletrônica}

A microscopia eletrônica permite visualizar (na rocha alterada e no solo) a morfologia dos constituintes mineralógicos e as relações existentes entre eles. As amostras indeformadas foram submetidas ao exame por MEV marca Jeol modelo - 5600 LV, acoplado à microssonda "Noran", com detector de fluoreto de lítio. Para isso, amostras (fragmentos de rocha alterada) foram estudadas e selecionadas em função dos problemas levantados pela microscopia óptica nas lâminas. As amostras foram inicialmente coladas em suporte de metal com cola de prata e em seguida nebulizadas com ouro ou carbono em um evaporador "Deton Vacuum Desk II".

\section{RESULTADOS E DISCUSSÃO}

Os resultados obtidos por microscopia óptica sobre a rocha sã (os riodacitos estudados na região de Pirajú) permitiram identificar macrofenocristais de plagioclásio (anortita 2\%), fenocristais de plagioclásio (albita 5\%), piroxênio (augita 3\%), opacos (ilmenita e Ti-magnetita $5 \%$, na forma de fenocristais e microfenocristais). A matriz (80 - 85\%) dessa rocha é composta praticamente pelos mesmos minerais citados, além de feldspato alcalino (ortoclásio) e quartzo. Os minerais presentes na matriz, apresentam textura de resfriamento rápido, onde o plagioclásio (albita) é mal formados, os piroxênios mostram-se ocos e a magnetita de forma esqueletal. Em algumas amostras ocorrem vesículas preenchidas por zeólitas (Figura 1).

A textura encontrada é classificada como fracamente porfirítica, pois, apresenta no máximo $5 \%$ de fenocristais. Quanto ao grau de cristalinidade, a rocha caracteriza-se como holocristalina por conter quase que a totalidade de componentes cristalinos. Os cristais de plagioclásio quando ocorrem na forma de fenocristais, são euhedrais à subhedrais, levemente zonados. Os macrofenocristais de plagioclásio são euhedrais, levemente zonados.

Os cristais de piroxênio são anhedrais (granulares) a subhedrais (prismáticos) e são representados principalmente por augita e secundariamente por pigeonita. Os piroxênios cálcicos (augita) são de cristalização precoce, ou seja, ocorrem como fenocristais, são mais enriquecidos em $\mathrm{Ca}$ do que
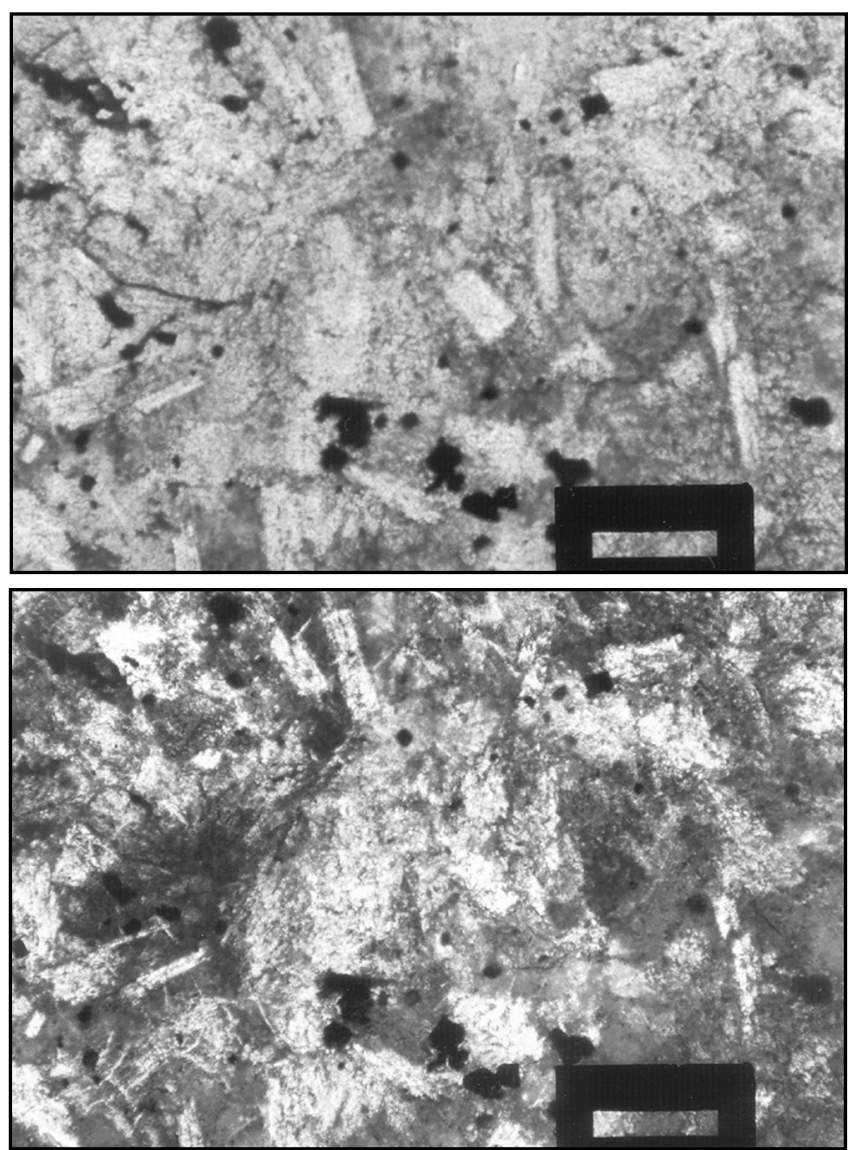

Figura 1 - Matriz fina da rocha riodacítica, ripas de plagioclásio piroxênio e opacos (na forma de fenocristais e microfenocristais). Microscópio óptico, luz natural, luz polarizada (nicóis cruzados), com aumento de x 2,5. 
aqueles de cristalização tardia (os que ocorrem como microfenocristais ou na matriz), que por sua vez, são mais enriquecidos em ferro (Nardy et al., 1986). As zeólitas são silicatos de alumínio com sódio e cálcio. São comuns em rochas de origem vulcânica, onde preenchem vacúolos formando as amígdalas durante a fase hidrotermal no resfriamento das lavas. As zeólitas são instáveis no meio ácido (Ming \& Mumpton, 1989), o que explica a sua ausência nos horizontes mais superficiais do perfil de solo, bem como em classes de solo com feições de intemperismo mais avançado.

Os minerais opacos ocorrem como fenocristais e microfenocristais, subhedrais, com forma granular e esqueletal.

Pela difração de raios- $X$ da fração argila total constatou-se uma mineralogia bastante simples: caulinita (dominante), gibbsita, esmectita e haloisita. Em todos os difratogramas analisados, há bastante semelhança das características mineralógicas, indicando a homogeneidade do material de origem (Figura 2).

Os reflexos de caulinita em todos os difratogramas são agudos e simétricos, sugerindo-se tratar de argilominerais de alta cristalinidade a 0,$72 ; 0,36$ e $0,35 \mathrm{~nm}$, os quais são eliminados pelo aquecimento a $550^{\circ} \mathrm{C}$.

A gibbsita mostra picos intensos em 0,48 e 0,43 $\mathrm{nm}$, sendo destruída pelo aquecimento a $350^{\circ} \mathrm{C}$. A formação de um pico próximo a 1,4 - 1,8 nm pode indicar a presença de esmectita. A haloisita ocorre com picos em 0,75 e $0,36 \mathrm{~nm}$ indicando serem de baixa frequência, podendo ser decorrência de uma desidratação natural ocorrida no campo.
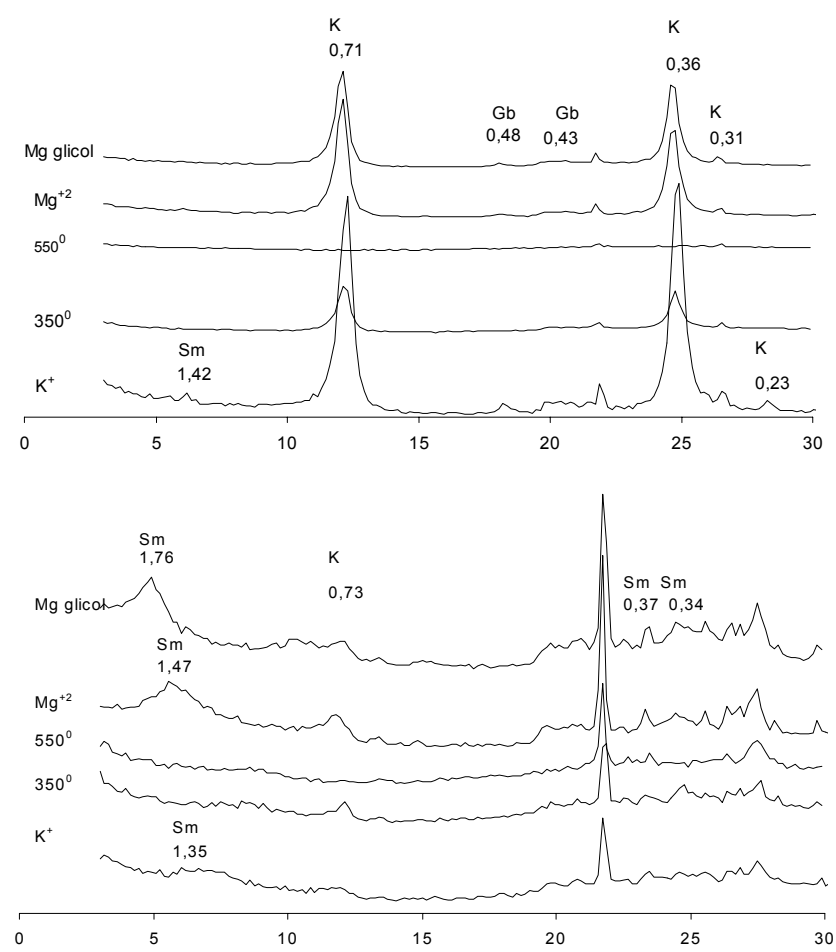

A instabilidade da haloisita, até em condições ambientes, torna-se como um constituinte incomum nos solos devido às condições de dessecação que são normalmente submetidas no seu ambiente natural (Dixon, 1966).

\section{Alteração dos plagioclásios}

A alteração de minerais foram detalhadas e descritas por inúmeros autores, entre eles: Leneuf (1959); Bonifas (1959), Delvigne (1965), Lelong (1969), Novikoff (1974) e Boulange (1984) citado por Clemente (1988), mostraram que as alterações dos plagioclásios evoluem de acordo com a situação geográfica da rocha de origem (clima, relevo etc.) e drenagem interna do perfil onde se encontra o mineral.

Os plagioclásios tendem a desagregar-se logo nos primeiros estádios de alteração, levando a rocha uma perda de coesão. Esta desagregação se traduz por um sistema de fraturas, que tende a se alargar à medida que a alteração progride. Essas modificações físicas estão intimamente relacionadas com as transformações químicas.

Em condições tropicais úmidas, regiões de elevada pluviosidade e boa drenagem o plagioclásio apresenta um tipo extremo de transformação. Tal alteração do plagioclásio pode ser diretamente para gibbsita, isto é, dependendo do microambiente, se a drenagem for muito intensa (Delvigne, 1965 e Clemente, 1988).

Em condições menos severas de intemperismo, as alterações seguem de outra maneira: plagioclásio $\rightarrow$ geles amorfo $\rightarrow$ gibbsita ou plagioclásio $\rightarrow$ geles amorfo $\rightarrow$ gibbsita + caolinita.
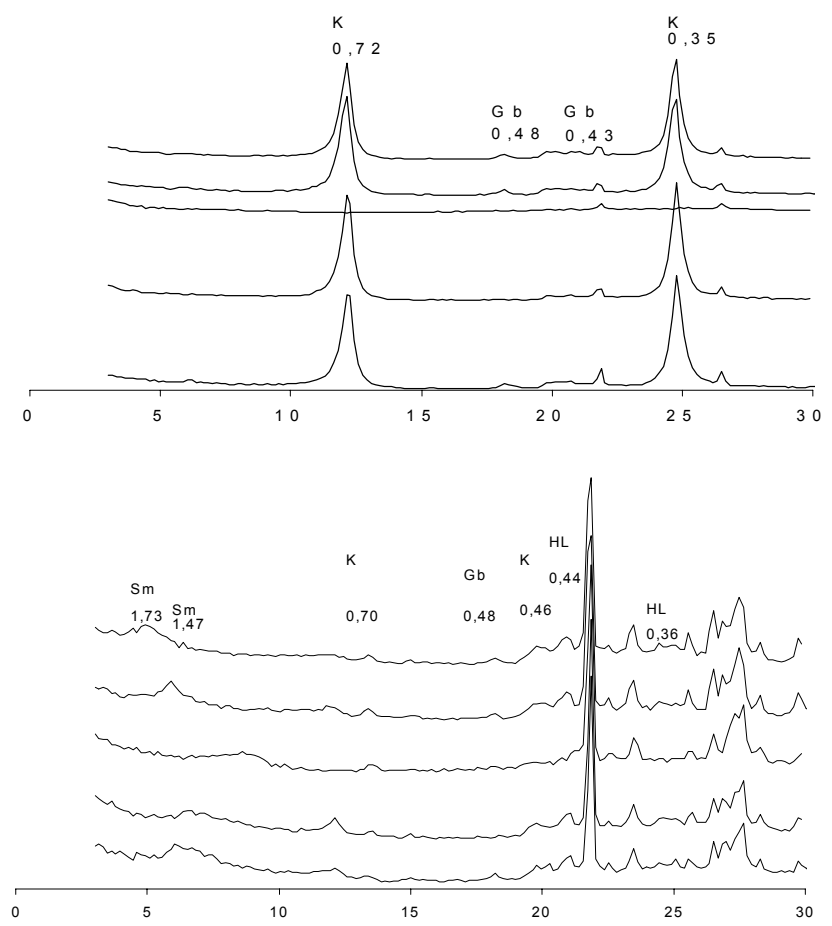

Figura 2 - Difratogramas de raios-x da fração argila, com identificação das distâncias interplanares: $\mathrm{K}=$ caulinita; $\mathrm{Gb}=$ gibbsita; HL = haloisita e $\mathrm{Sm}=$ esmectita. 
A rapidez com que as bases e a sílica são eliminadas dos níveis de alteração, determina o aparecimento da gibbsita (Delvigne, 1965). Se a exportação da sílica no ambiente de alteração é mais lento, uma parte da sílica se mantém combinada com o alumínio, causando o retardamento da destruição da estrutura, gerando o aparecimento de uma fase amorfa + caulinita. Esta fase amorfa + caulinita se mantém até a eliminação total do silício, quando se dá o aparecimento dos primeiros cristais de hidróxido de alumínio.

Em meio ferralítico, os produtos de alteração mais freqüentes dos plagioclásios são os argilominerais 1:1 (caulinita, haloisita e metahaloisita), materiais amorfos até gibbsita quando a dessilificação for mais intensa (Delvigne, 1965). Os fenocristais de plagioclásio se alteram de maneira uniforme (Bellieni et al., 1986b). Em todos os casos, as primeiras manifestações da alteração consistem no aparecimento de finas fraturas, de alguns micrômetros de espessuras, sinuosas e que não seguem geralmente os planos de clivagem. Essas fissuras são as vezes fracamente amareladas ou amareloavermelhadas por hidróxidos de $\mathrm{Fe}$ proveniente da alteração dos minerais vizinhos. Com o avanço da alteração, as finas fraturas sinuosas dividem o plagioclásio em algumas fases distintas. Os espaços entre essas fissuras são preenchidos ora por material isotrópico (hematita e goethita) ora por partes do cristal formando ilhas do plagioclásio inalterado.

A alteração dos plagioclásios em direção ao córtex, se inicia por uma microfissuração intensa (sem orientação preferencial no cristal) e pelas microexpansões das linhas de clivagem, evidenciadas pela deposição de plasma ocre amarelado, ferruginosos (Gonçalves, 1987). Das bordas para o centro, os plagioclásios são pseudomorfeados por um plasma incolor a amarelo-pálido, isotrópico.

A interpretação do intemperismo dos plagioclásios é muito complexa pois estes apresentam uma grande variabilidade composicional (Bouabid et al., 1995). Os resultados obtidos no estudo dos plagioclásios dos riodacitos da topossequência estudada não fogem as regras descritas pelos autores citados anteriormente. De maneira geral, os fenocristais de plagioclásio dos riodacitos da Formação Serra Geral na Região de Piraju se alteram de uma maneira aproximadamente uniforme. As primeiras manifestações de alteração consistem no aparecimento de finas fraturas, de alguns micrômetros de espessura e que não seguem geralmente os planos de clivagem. Essas fissuras são as vezes fracamente amareladas ou amarelo-avermelhadas proveniente da alteração de minerais vizinhos.

Uma segunda evidência de alteração sugere que o comportamento dos plagioclásios seja sua alteração para caulinita e secundariamente em mica e haloisita, isto é, quando as condições de intemperismo não forem muito intensas (Figura 3). Quando em condições severas de intemperismo, isto é, quando o processo de alitização for bastante intenso, é possível detectar a transformação dos plagioclásios em gibbsita (Figura 4). A análise química qualitativa evidencia o aparecimento somente do pico de Al e praticamente não se observa o de Si.

Nessa dissolução dos plagioclásicos ocorrem cavidades cujas superfícies, em seguida, são preenchidas por goethita (Glasmann \& Simonson, 1985). A relação das análises químicas pontuais da microscopia eletrônica associada com a morfologia dos cristais obtidos no microscópio eletrônico colocou em evidência a ocorrência de caulinita, também evidenciada pela ocorrência de picos de $\mathrm{Al}$ e $\mathrm{Si}$ praticamente equivalentes. A caulinita é o mineral de argila mais comum e pode ser identificada pelo formato hexagonal em placas características (Grim, 1968). Os cristais de caulinita se encontram distribuídos ao acaso, formando uma matriz com aspecto granular.
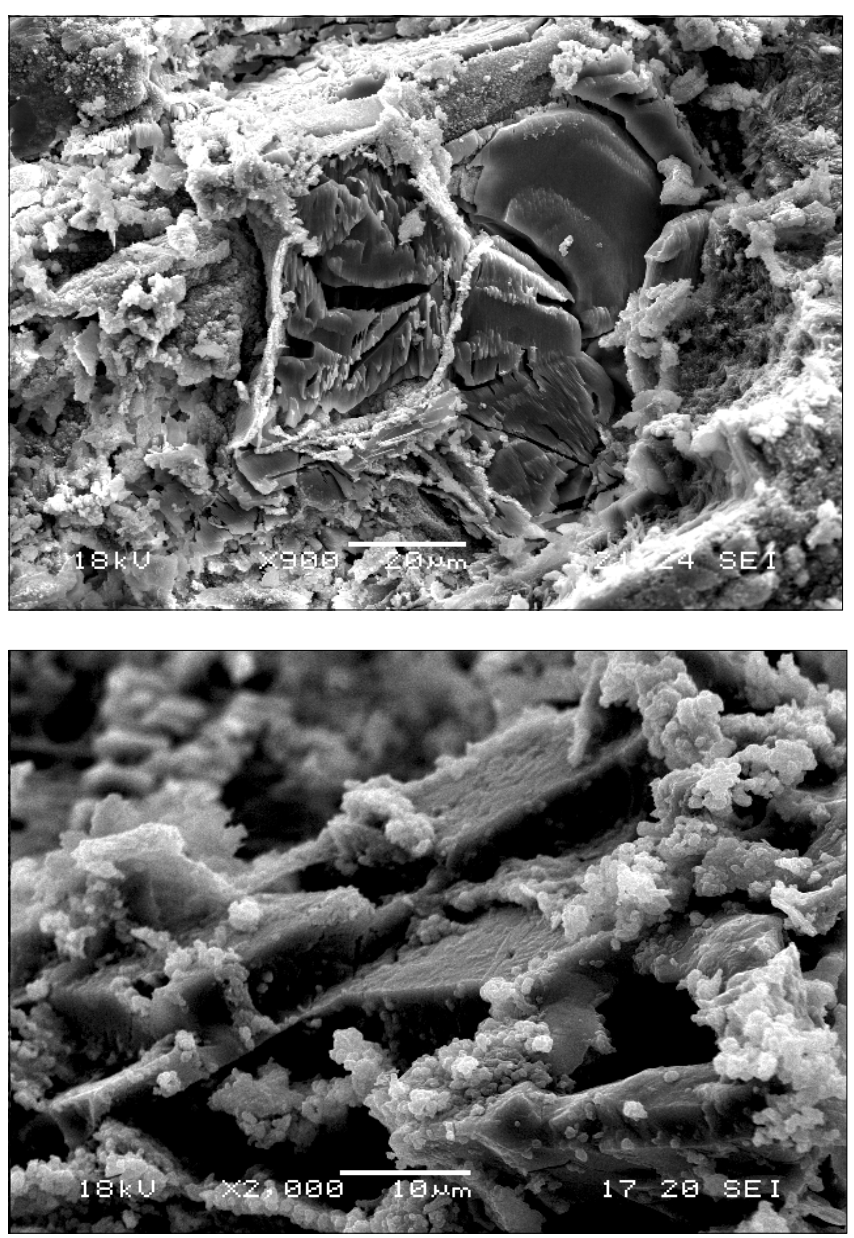

Figura 3 - Microscópio Eletrônico de Varredura, detalhe do plagioclásio sofrendo alteração. Os espaços deixados são totalmente ocupados por caulinitas. 

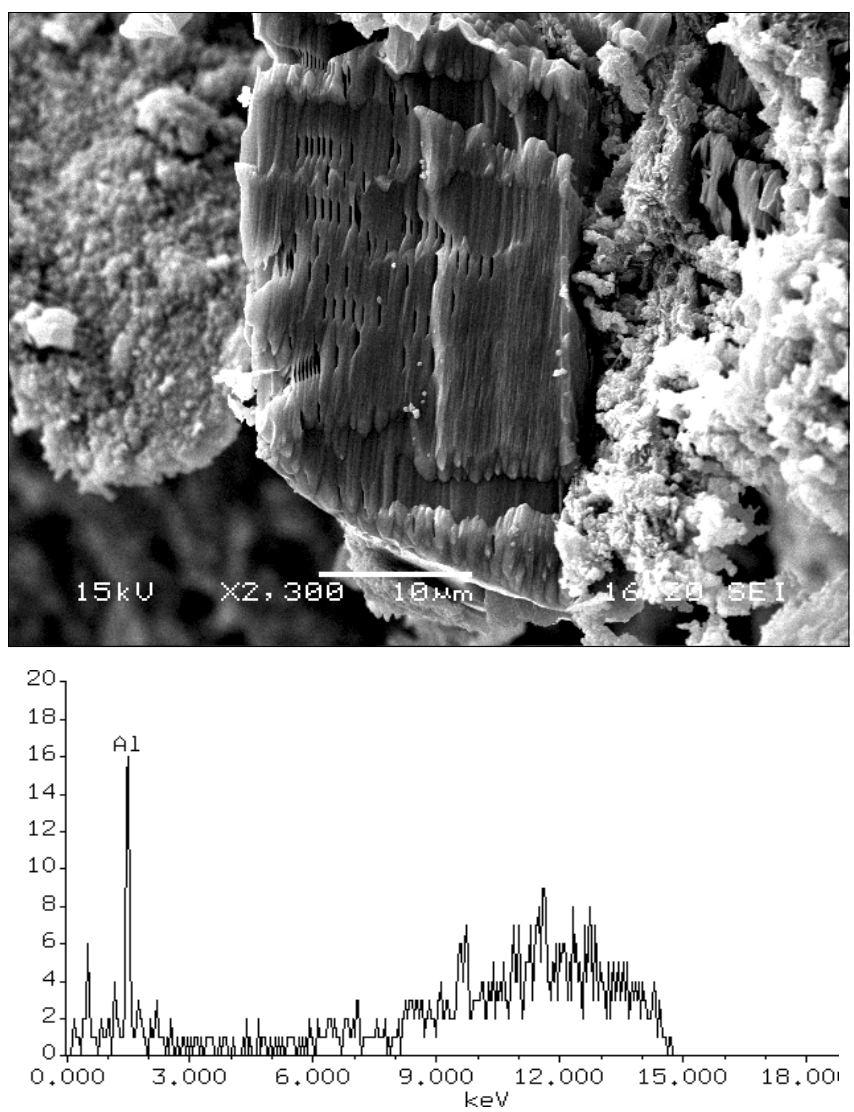

Figura 4 - Microscópio Eletrônico de Varredura, plagioclásio transformado diretamente em gibbsita. São evidentes as linhas de dissolução ao longo do plano do cristal. $\mathrm{O}$ ponto 1 refere-se a análise química qualitativa pontual realizada neste cristal.

\section{REFERÊNCIAS BIBLIOGRÁFICAS}

ALMEIDA, F.F.M. Síntese sobre a tectônica da Bacia do Paraná. In: SIMPÓSIO REGIONAL DE GEOLOGIA, 3., Curitiba, 1981. Atas. São Paulo: SBG, 1981.

BELLIENI, G.; COMIN-CHIARAMONTI, P.; MARQUES, L.S.; MARTINEZ, L. A, MELFI, A.J; NARDY, A.J.R.; PICCIRILLO, E.; STOLFA, D. Continental flood basalts from the central-western regions of the Paraná plateau (Paraguay and Argentina): petrology and petrogenetic aspects. Journal of Petrology, v.154, p.111-139, 1986a.

BELLIENI, G.; COMIN-CHIARAMONTI, P.; MARQUES, L.S.; MARTINEZ, L.A.; MELFI, A.J.; NARDY, A.J.R.; PAPATRECHAS, C.; PICCIRILLO, E.; ROISENBERG, A.; STOLFA, D. Petrogenetic aspects of acid and basaltic lavas from the Paraná plateau (Brazil): geological, mineralogical and petrochemical relationships. Journal of Petrology, v.27, p.915-944, 1986b.

BOUABID, R.; NATER, E.A. BLOOM, P.R. Characterization of the weathering status of feldspar minerals in sandy soils of Minnesota using SEM and EDX. Geoderma, v.66, p.137-149, 1995.

COMIN-CHIARAMONTI, P.; BELLIENI, G.; PICCIRILLO, E.; MELFI, A.J. Classification and petrography of continental stratoid volcanics and related intrusives from the Paraná Basin (Brazil). In: PICCIRILLO, E.; MELFI, A.J. The mesozoic flood volcanism of the Paraná Basin. São Paulo: USP- IAG, 1988. cap.3, p.47-72.
CLEMENTE, C.A. Alterações e solos desenvolvidos sobre rochas vulcânicas ácidas da Formação Serra Geral nos Planaltos de Guarapuava e Palmas, região centro-sul do Estado do Paraná. Piracicaba, 1988. 211p. Tese (Doutorado) - Escola Superior de Agricultura "Luiz de Queiroz", Universidade de São Paulo.

DELVIGNE, J. Pedogénese en zone tropicale. La formation des mineraux secondaires en milieu ferrallitique. Paris: Dunod, 1965. 177p. (Mén. Orstom, 13).

DIXON, J.B. Quantitative analysis of Kaolinite and gibbsite in soils by differential thermal and selective dissolution methods. In: CLAYS AND CLAYS MINERALS CONFERENCE, 14., New York, 1996. Proceedings. New York: Pergamon Press, 1966. p. 82-89.

GASPARETTO, N.V.L. Alteração intempérica de rochas vulcânicas ácidas na Região Central do Estado do Rio Grande do Sul, Brasil. São Paulo, 1990. p.168. Dissertação (Mestrado) - Instituto de Geociências, Universidade de São Paulo.

GONÇALVES, N.M.M. Transformações mineralógicas e estruturais relacionadas à alteração hidrotermal e intempérica de rochas vulcânicas básicas da Bacia do Paraná Setentrional - Região de Ribeirão Preto SP. Brasil. São Paulo, 1987. 212p. Tese (Doutorado) - Instituto de Geociências, Universidade de São Paulo.

GLASMANN, J.R.; SIMONSON, G.H. Alteration of basalt in soils of Western Oregon. Soil Science Society of America Journal, v.49, p.262-273, 1985.

GRIM, R.E. Clay mineralogy. 2.ed. New York: Mc-Graw-Hill, 1968. 596p.

IYOMASA, W.S. As rochas vulcânicas ácidas da Formação Serra Geral no vale do rio Paranapanema (SP/PR) In: CONGRESSO BRASILEIRO DE GEOLOGIA, 38., Camboriu, 1994. Resumos expandidos. Camboriu: SBG, 1994. p.107-108.

LEINZ, V. Contribuição à geologia dos derrames basalticos do sul do Brasil. São Paulo, 1949. 61p. Tese (Doutorado) - Faculdade de Filosofia, Ciências e Letras, Universidade de São Paulo.

LEVI, F.; MELFI, A.J. Geochimical and Mineralogical studies on the first stage of weathering of basic and related rocks. Part 2. Geochemical Study. Revista Brasileira de Geociências, v.2, p.1-7, 1972.

MELFI, A.J.; LEVI, F. Geochimical and Mineralogical study on the first stage of weathering of basic and related rocks. Part 1. Mineralogical Study. Revista Brasileira de Geociências, v.1, p.22-28, 1971.

MENEGOTTO, E.; GASPARETTO, N.V.L. Intemperização de rochas vulcânicas básicas e ácidas na região de Santa Maria - RS. In: CONGRESSO BRASILEIRO GEOGRAFIA, 1., Porto Alegre, 1987. Anais Porto Alegre, 1987, v.2, p.69-83.

NARDY, A.J.R.; MARQUES, L.S.; RAPOSO, M.I.B. Aspectos Petrológicos das rochas efusivas ácidas da Região Centro Sul do Estado do Paraná Revista Brasileira de Geociências, v.16, p.43-57, 1986

NARDY, A.J.R. Petrologia e paleomagnetismo das rochas vulcânicas da Região Centro-Sul do Estado do Paraná: Formação Serra Geral. São Paulo, 1987. 186p. Dissertação (Mestrado) - Instituto de Geociências Universidade de São Paulo.

MING, D.W.; MUMPTON, F.A. Zeolites in soils. In: DIXON, J.B.; WEED, S.B. (Ed.) Minerals in soil environments. 2.ed. Madison: SSSA, 1989. p.873911.

PICCIRILLO, E M : CIVETTA, L : PETRINI, R : LONGINELLI, A · COMINCHIARAMONT, P.; BELLIENI, G.; MARQUES, L.S.; MELFI, A.J. Regional variations within the Paraná continental flood basalt sequences as evidence for different mantle regions and variable crustal contamination. Terra Cognita, v.7, p.179-205, 1987.

RAPOSO, M.I.B. Evolução magmática e petrológica das rochas vulcânicas ácidas mesozóicas da Região de Piraju - Ourinhos (SP e PR). São Paulo, 1987. 159p. Dissertação (Mestrado) - Instituto de Geociências, Universidade de São Paulo.

RUEGG, N.R.; AMARAL, G. Variação regional da composição química das rochas basálticas da Bacia do Paraná. Boletim Instituto Geociências, v.7, p.131-147, 1976

SARTORI, L.L.; MACIEL FILHO, C. Petrografia das regiões ácidas da Formação Serra Geral na região do Rio Paranapanema - SP. Ciência e Natura, v.5, p.19-23, 1983

$\overline{\text { Recebido em } 19.02 .01}$ 